\title{
FUNCIONES Y HOMOLOGÍA FUNCIONAL EN LAS CIENCIAS COGNITIVAS
}

\author{
Claudia Lorena García \\ Instituto de Investigaciones Filosóficas \\ Universidad Nacional Autónoma de México \\ clga1305@gmail.com
}

RESUMEN: En este ensayo presento brevemente la propuesta de un concepto de homología funcional, junto con sus criterios empíricos. Argumento que dicho concepto es necesario para la articulación de una ciencia cognitiva evolutiva rigurosa y completa. Luego considero la pregunta sobre cuál de los dos principales conceptos de función que han sido desarrollados por filósofos de la biología — a saber, el análisissistémico o el seleccionista - es el que encaja de mejor manera con mi concepto de homología funcional, y concluyo que la noción de tipo sistémico (inicialmente propuesta por Robert Cummins) es la más coherente con dicho concepto.

PALABRAS CLAVE: evolución cognitiva, cladística, sistemas cognitivos, descendencia con modificaciones, sistemas funcionales

SUMMARY: In this paper, I sketchily present my proposal of a concept of functional homology, along with some empirical criteria. I argue that such concept is necessary for the construction of a rigorous and complete evolutionary cognitive science. Next, I consider the question as to which concept of function - whether a systems-analysis or a selectionist one - better fits my concept of functional homology, and conclude that the systems-analysis notion (originally proposed by Robert Cummins) coheres best with that concept.

KEY WORDS: cognitive evolution, cladistics, cognitive systems, descent with modifications, functional systems

\section{Introducción}

En la biología evolutiva contemporánea existe un par de conceptos de suma importancia — a saber, el de homología y el de homoplasiaque permiten responder preguntas acerca de la filogenia (i.e., la historia evolutiva) de los diferentes caracteres o rasgos de los organismos biológicos. Por ejemplo, los biólogos se preguntan si las alas de los pájaros y las de los murciélagos son homólogas, es decir, si provienen (con algunas modificaciones) de las alas del ancestro común más reciente de estos organismos. La respuesta es que el ancestro común más reciente de éstos no tenía alas, y que las alas de los pájaros y las de los murciélagos evolucionaron de manera independiente - lo cual significa que son rasgos homoplásticos (en particular, convergentes) y no homólogos - cuyas apariciones en los linajes correspondientes quizá se debieron a presiones ambientales similares. 
En las ciencias cognitivas, la mayoría piensa que por lo menos algunas de las capacidades cognitivas de los animales y de los humanos son el producto de alguno de los mecanismos que están involucrados en la evolución biológica. No obstante, hay una amplia gama de posiciones al respecto, desde aquellas según las cuales la mayoría de esas capacidades evolucionaron biológicamente, hasta aquellas que sostienen que sólo unas pocas lo hicieron. Al margen de quién está en lo correcto, subsisten importantes problemas "conceptuales" que todos ellos deben resolver para poder afirmar de manera coherente que algunas capacidades (mecanismos o sistemas) cognitivas son el resultado de la evolución biológica. Uno de estos problemas es articular un concepto de homología que pueda aplicarse a capacidades o sistemas cognitivos. Pero los sistemas cognitivos por lo general se entienden como sistemas funcionales de algún tipo - i.e., como sistemas que se individúan primordialmente en términos de alguna de sus funciones - por lo que para poder decir que dos sistemas funcionales son homólogos se necesita tener un concepto de homología funcional que sea adecuado y que esté empíricamente articulado. Pese a lo anterior, no existe un concepto de homología funcional como éste en ninguna rama de la biología; sólo se tiene un concepto de homología aplicable a rasgos morfológicos. Algunos biólogos moleculares y algunos biólogos del desarrollo en ocasiones afirman que ciertas entidades son funcionalmente homólogas; pero no parece haber un consenso entre ellos respecto a cómo entender estas afirmaciones, o cómo sustentarlas de manera empírica. ${ }^{1}$

Ahora bien, históricamente ha existido una gran controversia en cuanto a la forma en la cual la conducta de un organismo debe ser descrita cuando se estudia su historia evolutiva, i.e., si debe o no caracterizarse simplemente como un conjunto de patrones de movimientos físicos, considerando algunos efectos físicos de esa conducta en su ambiente, o incluso en términos funcionales más amplios. También se discute si deberían postularse mecanismos (o sistemas) cognitivos internos a fin de explicar las conductas.

Muchos ecólogos de la conducta - por ejemplo, los que trabajan con arañas, hormigas, artrópodos en general, peces y algunos pájaros - tienden a concebir las conductas como conjuntos de patrones estereotípicos de movimientos físicos, y a determinar la homología de las conductas de una forma que incluye estos patrones al

\footnotetext{
${ }^{1}$ Véanse las discusiones en la biología molecular del desarrollo entre, por ejemplo, Ehab Abouheif (1997 y 1999), Alessandro Minelli (1998), y Ann Butler y William Saidel (2000).
} 
igual que algunos de sus efectos físicos sobresalientes y regulares (por ejemplo, nidos, telarañas, etc.), tratando de evitar en la medida de lo posible tanto la descripción de la conducta desde un punto de vista funcional como la explicación de ésta en términos de la existencia de mecanismos cognitivos internos (de Queiroz y Wimberger 1993; Lee et al., 1996; Bosch et al., 2001; Benjamin y Zschokke 2004). En otras palabras, los estudiosos que comparten este enfoque tratan, en la medida de lo posible, de conceptualizar a las conductas como caracteres morfológicos.

Este enfoque, empero, ha probado ser en extremo limitado al aplicarse al estudio de las conductas más interesantes de los pájaros, los mamíferos y, más aún, los humanos. Este punto ha sido estudiado y discutido exhaustivamente a través de una parte significativa de la historia de numerosas disciplinas — desde la etología cognitiva y la psicología animal, hasta la ciencia cognitiva, la filosofía de la mente y de la psicología - ${ }^{2}$ En primer lugar, la casi total ausencia de conductas estereotípicas (aquellas que consisten de los mismos patrones de movimientos físicos) en muchos de los organismos complejos capaces de cognición, restringe radicalmente la aplicabilidad de un enfoque como el mencionado anteriormente. Una descripción funcional de las conductas resulta inevitable en estos casos. Se sabe también que la explicación de la mayoría de las conductas de organismos complejos requiere la postulación de mecanismos cognitivos internos (de alguna manera implementados en los cerebros de tales organismos) entendidos como procesadores de información de algún tipo.

Pero no sólo esto; hablar de homología en relación con conductas funcionalmente descritas quizá no será suficiente para apreciar el grado en el cual los rasgos cognitivos de organismos cognitivamente complejos se han conservado a través de la historia evolutiva de tales organismos, y la medida en la que han cambiado. Es probable que, aunque las conductas con la misma descripción funcional en organismos de dos especies cercanamente emparentadas no sean homólogas, haya casos en los cuales, una o varias de las capacidades cognitivas que generan esas conductas sí lo sean pues derivan de un ancestro común. Si esto es correcto, entonces será necesario subir al nivel de los sistemas cognitivos (i.e., al de los mecanismos que subyacen a esas capacidades cognitivas) y construir un concepto

${ }^{2}$ La etología cognitiva nació precisamente como resultado de darse cuenta de que muchas conductas animales no podían explicarse sin la postulación de mecanismos cognitivos internos entendidos como sistemas funcionales que procesan información de diferentes maneras. Véanse Heyes y Dickinson 1990, Beer 1991, Allen 1992, 2004, y Allen y Bekoff 1995. 
de homología funcional que nos permita detectar aquellos sistemas cognitivos que de alguna manera se han conservado evolutivamente con ciertos cambios, y aquellos que son evolutivamente novedosos (novel) - y esto es precisamente lo que he hecho en otra parte y que aquí resumo-.

Las preguntas respecto a si la capacidad para el lenguaje en los humanos es una novedad evolutiva - o si existe una capacidad en los bonobos o en algún otro de los grandes simios que en algún sentido interesante sea homóloga a nuestra capacidad lingüística (o a partes de esa capacidad) - sólo pueden responderse, digo yo, cuando tengamos un concepto aceptable y claro de homología funcional, al igual que un conjunto de criterios empíricos claros y plausibles para tal homología. Aquí bosquejo mis propuestas de un concepto de homología funcional y de ciertos criterios para la aplicación empírica de este concepto que son análogos a algunos criterios que en la actualidad se usan en la morfología comparada — propuestas que ya defendí en otras partes con mayor detalle- ${ }^{3}$

$\mathrm{Si}$ el concepto de homología funcional que propongo se acepta, para poder afirmar que la capacidad comunicativa en los bonobos y la capacidad lingüística en los humanos no descendieron de una capacidad cognitiva presente en un ancestro común no basta con demostrar que tales capacidades son diferentes (incluso muy diferentes); esto sería como decir (falsamente) que los huesos de las mandíbulas inferiores de los reptiles y los huesos del oído medio de los mamíferos no son homólogos ya que son morfológica y funcionalmente tan diferentes. Como veremos, lo que uno requiere para poder afirmar o negar que las capacidades cognitivas antes mencionadas en bonobos y en humanos son homólogas es realizar comparaciones sistemáticas globales parecidas a las que se llevan a cabo en la morfología comparada usando varios criterios incluyendo el análisis cladístico. Cómo llevar a cabo tales comparaciones y qué concepto de función involucra esto, son precisamente los temas de este ensayo.

\section{Homología y analogía morfológicas}

Richard Owen (1804-1892) acuñó los términos "homología" y "analogía" definiéndolos de la siguiente manera: un homólogo "es el mismo órgano en diferentes animales bajo diferentes formas y funciones... [En contraste, un análogo es una] parte o un órgano en un animal que tiene la misma función que otra parte u órgano en un animal diferente" (Owen 1843, pp. 379 y 374). Con Darwin, la idea

${ }^{3}$ Véanse García 2010 y 2013. 
intuitiva asociada a la homología se transformó así: puede existir una línea histórico-evolucionista entre ciertas estructuras u órganos de organismos que pertenecen a especies distintas, aun cuando estas estructuras $\mathrm{u}$ órganos sean morfológica o funcionalmente muy disímiles. ${ }^{4}$ De acuerdo con esto, el término "homología" se refiere a una mismidad debida a la existencia de un ancestro común - pese a que no existan semejanzas importantes de carácter morfológico o funcional-.

Pero, ¿cómo puede un biólogo evolutivo determinar cuáles rasgos son homólogos y cuáles no? Que haya muchas e importantes semejanzas entre dos rasgos no es suficiente para concluir la homología ya que esto es compatible con la hipótesis de convergencia. En sentido opuesto, el que dos rasgos sean muy diferentes tampoco es suficiente para concluir que no son homólogos. Demostrar la existencia de un ancestro común con un rasgo muy parecido tampoco es decisivo, y en la mayoría de los casos es impracticable, ya que el putativo ancestro común está extinto y no se tiene registro fósil de su existencia o tal registro es irremediablemente incompleto.

Por fortuna, en la actualidad algunas ideas gozan de cierta aceptación respecto a los criterios empíricos que deben usarse en la corroboración de hipótesis de homología morfológica. ${ }^{5}$ Estos criterios se derivan sobre todo del trabajo de dos investigadores clave en los años cincuenta: Remane (1952) y Hennig (1950). Estos criterios son epistemológicos pues establecen los tipos de evidencia que cuentan en favor de una hipótesis de homología, pero es importante enfatizar que no son condiciones necesarias ni suficientes para la homología. De hecho, se piensa que cuantos más de estos criterios se cumplan con mayor claridad, más corroboradas estarán las hipótesis de homología correspondientes. Existen dos pasos en la corroboración de homologías morfológicas:

A. Homología primaria: en este paso se usan tres criterios para identificar y corroborar homologías, e involucra comparaciones de cierto tipo entre dos rasgos de dos organismos diferentes. Las hipótesis de homología resultantes en este nivel son todavía tentativas. Los criterios de los que consta la homología primaria son:

${ }^{4}$ Una presentación más completa de la historia del concepto de homología morfológica se encuentra en Laubichler 2000.

${ }^{5}$ Al final de esta sección se examinan de modo breve algunas controversias que han surgido y que siguen vigentes en cuanto a la manera en que debe entenderse el concepto de homología y a los criterios empíricos que deben regir su aplicación. 
Criterio 1. Posición relativa: dos partes u órganos son homólogos cuando ocupan la misma posición relativa en los organismos respectivos — donde "posición" quiere decir "la misma posición topológica"- La idea es que si se pueden encontrar suficientes correspondencias morfológicas entre los diferentes órganos o partes de dos organismos diferentes de manera tal que se pueda hablar de la "misma posición" de aquellos dos órganos, entonces esto constituye evidencia en favor de la hipótesis de homología (i.e., evolutivo-filogenética) entre esos órganos. En la etología se usa un criterio análogo para la conducta: dos conductas son homólogas cuando ocupan la misma posición en un patrón de conducta más general (por ejemplo, dos formas diferentes de mover la cola son homólogas cuando ocurren en el mismo "lugar" en rituales de cortejo).

Criterio 2. Cualidad especial: esto hace referencia a la complejidad y/o distintividad de dos rasgos en dos organismos; la idea es que entre más especializados y/o complejos son esos rasgos, menos probable es que hayan evolucionado independientemente, y más probable es que sean el mismo (tipo de) rasgo - i.e., que sean homólogos-.

Criterio 3. Continuidad de Remane: este criterio se satisface cuando los rasgos en cuestión pueden localizarse dentro de una serie evolutiva de rasgos que empieza con los más simples y continúa hacia rasgos incrementalmente más complejos. La idea es que la posibilidad de localizar esos rasgos dentro de un continuo evolutivo gradual es evidencia de que tales rasgos son homólogos -i.e., están relacionados filogenéticamente- Este criterio también puede usarse para determinar la polaridad de un rasgo; en este caso se considera que las formas más simples del rasgo son evolutivamente más antiguas que las formas más complejas.

Nótese que aquí incluyo únicamente tres criterios de homología primaria - el de posición relativa, el de cualidad especial y el de continuidad - aunque algunos investigadores incorporan más criterios en este primer paso; por ejemplo, hay quien habla de un criterio ontogenético (i.e., mismidad de precursores ontogenéticos como evidencia de homología primaria (Hawkins et al., 1997)), mientras que otros prefieren considerar una mismidad en estructura (morfológica) como un criterio de homología primaria (Brower y Schawaroch 1996). Muchos de los estudiosos involucrados en esta controversia coinciden en que el criterio de posición relativa - también conocido como el criterio de topología (Agnarsson y Coddington 2008), 
el de homología topográfica (Jardine 1969) y el de identidad topográfica (Brower y Schawaroch 1996) - es un criterio importante (incluso, el más decisivo) en la determinación de la homología primaria.

Esta discusión sobre cuáles son los criterios apropiados en la elección de una hipótesis de homología primaria persiste en la actualidad; e.g., Agnarsson y Coddigton (2008, p. 52) argumentan que "la efectividad de los criterios de homología [primaria] puede variar dependiendo del dominio biológico del problema". En particular, ellos muestran que en la determinación de la homología de los escleritos genitales de arañas macho, el criterio de topología funcionó mejor que otros (como el de cualidad especial), ya que las homologías primarias que se basaron en el criterio de topología "resultaron en hipótesis que fueron globalmente más parsimoniosas que aquellas que se basaron en otros criterios" (Agnarsson y Coddigton 2008, p. 51). No obstante, ellos advierten que no debería generalizarse este resultado a todos los casos de homología morfológica, pues existen rasgos cuya posición relativa varía considerablemente en especies cercanamente emparentadas y que sin embargo son considerados buenos candidatos a homologías por otros criterios.

Ahora bien, las razones por las cuales escojo posición relativa, cualidad especial y continuidad como los criterios de homología cognitiva primaria se aprecian con mayor claridad en otro trabajo mío (García 2013), en el cual muestro que estos criterios son potencialmente aplicables al caso del sistema cognitivo de reconocimiento de caras en primates no humanos y humanos. La idea central es que pueden encontrarse análogos funcionales de estos criterios morfológicos, que tienen resultados interesantes al aplicarse a capacidades cognitivas. Por ejemplo, existen características peculiares — "especiales" - de los sistemas de reconocimiento de caras tanto en macacos, como en chimpancés y humanos que no tienen otros sistemas de reconocimiento visual - por lo que los criterios de cualidad especial y de continuidad son evidentemente aplicables en este caso-. Con todo, es posible que mi decisión respecto a cuáles son los criterios de homología primaria más apropiados al caso de otras capacidades cognitivas sea modificada a la luz de consideraciones empíricas relativas a las características de esas capacidades que típicamente tienden a conservarse a través de la evolución. Por otra parte, excluyo de la homología primaria el llamado "criterio ontogenético" puesto que, como propongo en la siguiente sección, las consideraciones ontogenéticas a nivel cognitivo (i.e., aquellas relativas al desarrollo cognitivo), al igual que las consideraciones ontogenéticas a nivel neurocerebral 
se incluyen en la etapa final de la homología secundaria, en la cual se construyen cladogramas que incluyen caracteres ontogenéticos de estos dos niveles. ${ }^{6}$

B. Homología secundaria: en este paso que involucra comparaciones entre muchos rasgos de diferentes especies se usa el análisis cladístico aplicado a las hipótesis del paso anterior. Este criterio se conoce también como el "criterio de congruencia". Las hipótesis de homología en el nivel secundario son "el resultado de un análisis de detección de patrones" (de Pinna 1991, p. 382) llamado "análisis cladístico". Como parte de este análisis, existe un método para la construcción de cladogramas -i.e., estructuras filogenéticas en forma de árbol- llamado el "método de la parsimonia". El principio cladístico de parsimonia sostiene que, de entre los diferentes cladogramas que pueden en principio ser construidos para un grupo de taxones, "aquel que está más apoyado por la evidencia es el que requiere que postulemos el menor número de cambios evolutivos". (Futuyma 1998, p. 97) y, por ende, el que "maximiza las proposiciones de homología" (de Pinna 1991, p. 383). Veamos un ejemplo (de Pinna 1991, pp. 382-383). En la siguiente tabla de la p. 11 tenemos una matriz de distribución de 27 rasgos o caracteres entre ocho taxones $(\mathrm{A}-\mathrm{H})$. Los caracteres 1-10 especifican el grupo formado por los taxones A-D; los caracteres 11-20 determinan el grupo E-H. El carácter 21 determina $\mathrm{AB}$, el carácter 22 determina EF. Los caracteres 23-27 determinan la agrupación BCFG.

\footnotetext{
${ }^{6}$ Está asimismo el criterio de conjunción que postula Patterson (1988, p. 605) para la homología primaria, según el cual "si dos presuntos homólogos se encuentran juntos en un organismo, no pueden ser homólogos. Por ejemplo, la teoría de que el brazo humano (una extremidad superior de un mamífero) y las alas de los pájaros son homólogas estaría equivocada si en algún momento se descubrieran los ángeles (que tienen brazos $y$ alas)". Como bien menciona un dictaminador anónimo del presente ensayo, no sería conveniente postular este criterio de homología primaria para el caso de homologías cognitivas si resultase que existen módulos cognitivos y/o cerebrales que tienen la tendencia a ocurrir más de una vez en la arquitectura cognitiva y/o cerebral de, e.g., primates humanos o no humanos.
} 


\begin{tabular}{|l|l|l|l|l|l|l|}
\hline TAXA & & & & & & \\
\hline A & 11111 & 11111 & 00000 & 00000 & 10000 & 00 \\
\hline B & 11111 & 11111 & 00000 & 00000 & 10111 & 11 \\
\hline C & 11111 & 11111 & 00000 & 00000 & 00111 & 11 \\
\hline D & 11111 & 11111 & 00000 & 00000 & 00000 & 00 \\
\hline E & 00000 & 00000 & 11111 & 11111 & 01000 & 00 \\
\hline F & 00000 & 00000 & 11111 & 11111 & 01111 & 11 \\
\hline G & 00000 & 00000 & 11111 & 11111 & 00111 & 11 \\
\hline H & 00000 & 00000 & 11111 & 11111 & 00000 & 00 \\
\hline
\end{tabular}

El siguiente dibujo muestra dos de los cladogramas posibles que pueden construirse con los datos de la tabla anterior; el de la izquierda ("análisis de parsimonia") maximiza los enunciados de homología (28 en total) mientras que el de la derecha ("otro método") resulta solamente en 22 enunciados de homología:

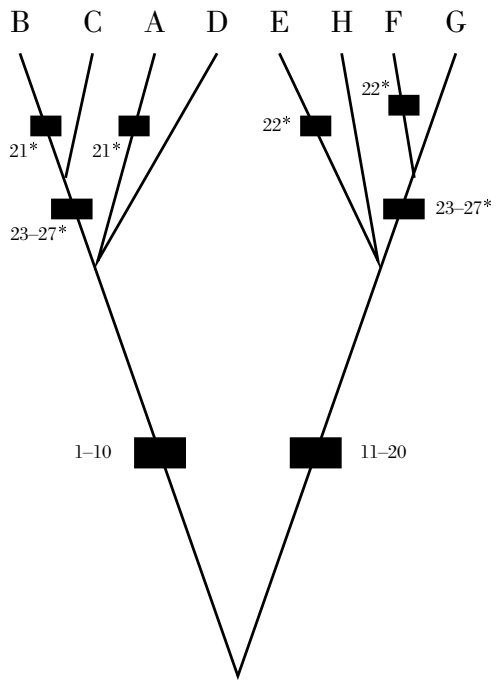

Análisis de parsimonia

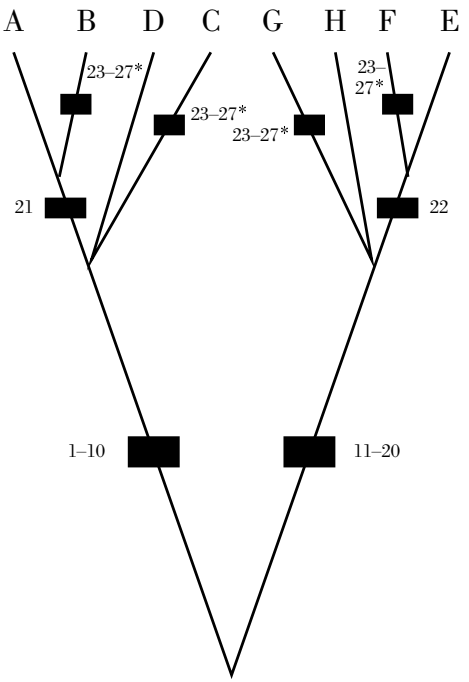

Otro método de análisis

En el cladograma anterior del análisis de parsimonia, por ejemplo, los caracteres 11-20 son homólogos en los taxones E, H, F y G, mientras que los 1-10 son homólogos en los taxones A, B, 
C y D. En contraste, los caracteres 23-27 en los taxones B y C no son homólogos a los caracteres 23-27 en los taxones F y G.

Es importante mencionar que el concepto de homología ha estado rodeado de muchos debates, incluso antes de que Darwin presentara su teoría de la evolución de las especies. Estas controversias han tenido que ver con preguntas tales como: (a) si existe (o debería existir) un único concepto de homología para todas las diferentes disciplinas biológicas, (b) cómo este (o estos) concepto(s) debería(n) entenderse, (c) su relevancia en el estudio de la evolución, (d) la naturaleza de los criterios empíricos que deberían usarse para detectar y confirmar hipótesis de homología, etcétera.

A mediados del siglo XX las principales discusiones sobre el concepto de homología se dieron entre los filogenetistas hennigianos o cladistas, y los sistématas evolutivos. Los cladistas aceptaban que el método de la construcción de cladogramas parsimoniosos era la principal (si no es que la única) herramienta para la reconstrucción de la filogenia y entendían a la homología en términos de la noción de sinapomorfia, o sea, la de un carácter derivado que es compartido por dos o más grupos y que se originó en el último ancestro común a esos grupos (Patterson 1982, de Pinna 1991). Por su parte, los sistématas evolutivos como Mayr (1969) pensaban que la construcción de cladogramas parsimoniosos no era suficiente para la reconstrucción de la filogenia ${ }^{7} \mathrm{y}$, por ende, rechazaban aquella manera puramente cladista (o metodológica) de entender la homología. La discusión entre cladistas y filogenetistas evolutivos al parecer se decidió finalmente en favor del cladismo.

En los años setenta y ochenta, surgen y se consolidan casi al mismo tiempo la filogenia molecular - es decir, los intentos por reconstruir la filogenia usando secuencias de $\mathrm{ADN}$ - y varios métodos computacionales para la construcción de cladogramas (por ejemplo, Kluge y Farris 1970, Fitch 1971). El uso preferencial de datos moleculares sobre los datos morfológicos en la reconstrucción de la filogenia usando algoritmos computacionales cada vez más complejos es en la actualidad una práctica generalizada. Esto ha dado lugar a una fuerte discusión entre aquellos cladistas que defienden la forma en que se usan los datos moleculares y los algoritmos computacionales (por ejemplo, Farris 2011, Nixon y Carpenter 2012, y Kluge 1993),

${ }^{7}$ Para los cladistas, cada taxón debe consistir de un único nodo ancestral y todos sus descendientes; mientras que la taxonomía evolutiva admite que se excluyan algunos grupos de su taxón parental, permitiendo así taxones parafiléticos (por ejemplo, no se piensa que el grupo de los dinosaurios incluya a los pájaros, sino más bien que aquéllos originaron a éstos). 
y aquellos que objetan estas prácticas (entre otros, Mooi y Gill 2010, Platnick 2013, Nelson 2011, Williams et. al 2011). ${ }^{8}$ Una de las objeciones contra aquéllos es que usan cualquier dato sobre cualquier secuencia de ADN como si fuera una evidencia relevante y apropiada, sin haber analizado de los caracteres antes de la construcción de los árboles filogenéticos y desconociendo si tal secuencia tiene o no alguna relación importante con algún rasgo fenotípico del organismo en cuestión. También se critica que las ausencias de ciertos caracteres (tanto moleculares como morfológicos) cuenten a su vez como caracteres. ${ }^{9}$ Respecto del concepto de homología, los que cuestionan las prácticas actuales tienden a defender la idea de que la homología debe entenderse exclusivamente en términos de la noción de sinapomorfia, mientras que los defensores de aquellas prácticas argumentan que la homología debe definirse de forma más amplia como plesiomorfia - es decir, la de un carácter ancestral presente en un taxón actual y que estuvo presente en sus ancestros - o incluso como simplesiomorfia —o sea, un carácter plesiomórfico que es compartido por dos taxones que no están anidados uno en el otro (Nixon y Carpenter 2012)-.

Además, algunos biólogos han sugerido que el concepto de homología debe determinarse más bien en términos de algún tipo de base causal - postulando que dos caracteres son homólogos cuando comparten el mismo tipo de mecanismo causal subyacente- En consecuencia, argumentan que, de no existir esta base causal subyacente compartida entre cualesquiera dos caracteres homólogos, el concepto de homología carecería por completo de interés teórico, ya que, si se establece que la homología es una mismidad debida a la existencia de un ancestro común, se requeriría una explicación enraizada en una mismidad estructural más profunda. ${ }^{10}$ Por ejemplo, Günther P. Wagner propone que dos caracteres sean considerados homólogos cuando el mismo conjunto de redes genéticas regulatorias formen parte de sus desarrollos ontogenéticos (2007). Ésta y otras propuestas respecto a la existencia de una supuesta base causal que

\footnotetext{
${ }^{8}$ Entre los métodos computacionales que se usan en las reconstrucciones filogenéticas están los que se conocen como "máxima verosimilitud" e "inferencia bayesiana". Para una defensa del uso de métodos bayesianos en este contexto, véase el libro de Elliott Sober (2008).

${ }^{9}$ No debe confundirse la "ausencia" con la "pérdida" de un carácter: tradicionalmente, éstas, más no aquéllas, contarían como caracteres. Un ejemplo de pérdida de un carácter es la carencia de extremidades en las serpientes; en contraste, una ausencia sería la carencia de agallas en las serpientes.

${ }^{10}$ Véanse Müller 2003 y Laubichler 2000.
} 
explica la existencia de la relación homológica entre dos caracteres están todavía bajo una discusión muy fuerte entre los estudiosos de estos temas en biología, y aún no hay consenso a cerca de cuál de todas estas propuestas debe aceptarse, si es que alguna (Rieppel 2007 y Striedter y Northcutt 1991). Algunos investigadores enfrascados en esta discusión tienden a pensar que, implícito en este tipo de propuestas, hay un reduccionismo biológico más generalizado, que a todas luces es inaceptable (Hall 2003 y Müller 2003).

Por último, debe decirse que se está debatiendo la individuación de los caracteres de los organismos biológicos. Hay quienes piensan que ésta es irremediablemente subjetiva pues aparentemente no se dispone de criterios claros ni objetivos para llevar a cabo tal individuación al construir las filogenias correspondientes y, por tanto, al determinar la aceptabilidad de ciertas hipótesis de homología. Esta discusión es de suma trascendencia en cuanto al grado de objetividad que se le pueda asignar a cualquier hipótesis de homología. Como ya vimos antes, el principio de parsimonia se usa en el paso de homología secundaria cuando se intenta determinar la aceptabilidad o inaceptabilidad de alguna hipótesis de homología. Este principio nos dice que, entre varios posibles cladogramas que puedan construirse para un grupo de taxones, debemos escoger el que postule el menor número de cambios evolutivos. Empero, es claro que el número de cambios evolutivos que postule un determinado cladograma dependerá del número de caracteres involucrado (Richards 2003), y este número a su vez depende de la estrategia de individuación de caracteres que se adopte en un momento dado. Así, dos estrategias diferentes de individuación de caracteres con frecuencia apoyan distintos cladogramas que son igualmente parsimoniosos, y que conllevan hipótesis de homología diferentes e incompatibles. De hecho, en la biología, diferentes disciplinas adoptan con frecuencia diferentes modos de individuar caracteres. ${ }^{11}$ Algunos estudiosos consideran que no hay razones para pensar que existirá una única estrategia de individuación de caracteres ni para pensar que tal estrategia única deba existir (Richards 2003). ${ }^{12}$ Esto sin embargo tendría implicaciones muy serias de carácter instrumentalista respecto a las hipótesis filogenéticas derivadas del método de la parsimonia.

Por falta de espacio, aquí no puedo ahondar en estas discusiones alrededor del concepto de homología en general y de sus criterios; pese a ello, la forma en la cual eventualmente se resuelvan quizá

${ }^{11}$ Véase Griffiths 2006.

${ }^{12}$ Cfr. Rieppel y Kearney 2007. 
tendrá un impacto en la aceptabilidad del concepto de homología funcional que propongo. ${ }^{13}$ Por ejemplo, la pregunta relativa a la individuación de caracteres, en el contexto de la homología funcional, involucra cuestiones muy difíciles en cuanto a la individuación de los sistemas funcionales y su estatuto ontológico — cuestiones acerca de los criterios epistemológicos para la identificación e individuación de sistemas funcionales, las condiciones epistemológicas en las cuales la postulación de un sistema funcional puede ser considerada como ontológicamente sustancial, etcétera.-

\section{Homología funcional y las ciencias cognitivas}

Por varias razones, algunas de las cuales menciono en la introducción, aquí asumo que no puede construirse una ciencia cognitiva evolucionista aceptable — una que postule de manera irreducible sistemas cognitivos en sus explicaciones - sin una noción de homología que sea aplicable a sistemas o mecanismos cognitivos. Pero los sistemas cognitivos - sin importar cómo los conciba uno, ya sea como máquinas de Turing o como redes neurales - son entidades funcionales, es decir, entidades que se individúan en términos de alguna de sus funciones. Así, elaborar una noción adecuada de homología que sea aplicable a sistemas cognitivos involucra la construcción de una noción apropiada de homología funcional.

Recordemos que los biólogos entienden la homología morfológica como: el mismo órgano o parte bajo diferentes formas y funciones; una mismidad que se explica en términos de la existencia de un ancestro común - ésta es la definición clásica de Owen vista a través del lente darwiniano- - Pero, ¿podríamos construir una noción de homología funcional análoga a este concepto de homología morfológica? Sería algo así como: la misma función bajo diferentes formas y funciones, lo cual en principio no tiene sentido; parecería que lo que aquí

\footnotetext{
${ }^{13}$ Mi propuesta de un concepto de homología funcional podría tener un destino distinto dependiendo de cuál teoría de una base causal para la homología se acepte finalmente (si es que se acepta alguna). $\mathrm{Si}$, por ejemplo, se acepta la teoría de Wagner, entonces creo que es muy improbable que exista una base causal uniforme a nivel de las redes genéticas regulatorias, para los sistemas cognitivos que, de acuerdo con mi teoría, probablemente serían funcionalmente homólogos (por ejemplo, el sistema cognitivo de reconocimiento de caras en algunos primates; véase García 2013). La principal razón para pensar esto es que creo que hay distintos niveles de organización biológica (por ejemplo, el nivel morfológico, el ontogenético, el genético, etc.) que no son reducibles unos a otros y que, con todo, están relacionados causalmente de maneras interesantes (véase Striedter y Northcutt 1991, quienes defienden algo muy parecido).
} 
requerimos es una manera de caracterizar diferencias funcionales que sean simultáneamente clasificables como correspondiendo a la misma función. En lo que sigue, voy a articular claramente un concepto de homología funcional semejante al de homología morfológica en los aspectos de importancia, y que evita este problema conceptual. ${ }^{14}$

Mi propuesta se funda en articular un concepto de homología funcional aplicable a sistemas funcionales. Un sistema funcional $S$ es una entidad que lleva a cabo por lo menos una función $F$ y que se individúa, por lo menos en ciertos contextos, primordialmente por referencia a alguna de sus funciones. Puede o no tener una estructura funcional interna -i.e., puede o no estar constituida por subsistemas funcionales cada uno de los cuales ejecuta una función distinta $F_{i}\left(i=1, \ldots, n\right.$ y $\left.F_{i} \neq F\right)$ que es necesaria para que $S$ realice $F$. Si un sistema funcional está constituido por subsistemas funcionales, entonces lo llamaremos un "sistema funcionalmente estructurado". Si no lo está, entonces diremos que es un "sistema no estructurado funcionalmente".

Aquí estoy concibiendo a la estructuración funcional de un sistema como algo que se da en un mismo nivel de descripción. Por ejemplo, cuando se concibe a la memoria de trabajo humana como un sistema cognitivo funcional de almacenamiento de información que consta de otros sistemas cognitivos (bucle fonológico, almacén, etc.) concatenados de ciertas maneras, se le está pensando como un sistema cognitivo estructurado funcionalmente a partir de otros subsistemas cognitivos, y la descripción de la estructuración funcional de tal sistema está dada por completo en el nivel cognitivo de descripción. Por otra parte, cuando la operación de un sistema funcional $S$, que en un principio es descrito a un cierto nivel - pongamos, al nivel cognitivo-, es descrita posteriormente a un nivel "más básico" — pongamos, al nivel cerebral- diremos que los procesos que se mencionan en este segundo nivel implementan el sistema cognitivo. ${ }^{15}$ Así, desde mi punto de vista, implementación y estructuración funcional son dos maneras distintas de describir cómo opera un sistema o mecanismo.

Ahora bien, el núcleo de mi propuesta de homología funcional surge de un intento por articular la idea preteórica de que hay una

${ }^{14}$ Love (2007) también intenta hacer esto, pero no creo que lo logre de manera satisfactoria. Esto es parte de lo que argumento en García 2010. Allí sostengo que lo postulado por Love tiene problemas serios, el menor de los cuales radica en una carencia de claridad que dificulta su evaluación profunda.

${ }^{15}$ Véase Craver (2001), quien piensa que la estructuración funcional necesariamente implica descender a un nivel de descripción más básico. 
distinción entre lo que algo hace y cómo lo hace. Esta idea será explicada de diferentes maneras en relación con sistemas funcionalmente estructurados en comparación con los no estructurados. En cuanto a sistemas estructurados, a la pregunta, "¿qué es lo que $S$ hace?", la respuesta es " $F$ ", cuando $F$ es una de las funciones que desempeña $S$. Por otra parte, a la pregunta, "¿Cómo es que $S$ hace $F$ ?", la respuesta está en describir cada una de las funciones que lleva a cabo cada uno de los subsistemas funcionales de $S$, y cómo tales funciones se concatenan para que $S$ ejecute $F$. Por otra parte, en el caso de sistemas no estructurados, la respuesta a la pregunta "¿Qué?" es del mismo tipo que para sistemas estructurados, pero la respuesta a la pregunta "¿Cómo?" es una descripción de la forma en que el desempeño de $S$ al llevar a cabo $F$ se implementa a un nivel de descripción inferior - p. ej., al nivel de procesos cerebrales, o a uno de interacciones moleculares-. Nótese que este tipo de respuesta a la pregunta "¿Cómo... ?" —i.e., una respuesta de tipo implementacional - también puede darse para el caso de sistemas funcionalmente estructurados.

Estoy ya en posición de proponer la siguiente caracterización de la homología funcional: Sistemas funcionales $\mathrm{Sl}$ del organismo $\mathrm{O} 1$ y $\mathrm{S} 2$ de $\mathrm{O} 2$ son funcionalmente homólogos cuando:

a. S1 y S2 pueden llevar a cabo la misma función $\mathrm{F}$, quizá de una manera distinta, ya sea que $\mathrm{F}$ se implemente de manera diferente en $\mathrm{S} 1$ y $\mathrm{S} 2$ (en el caso tanto de sistemas estructurados como no estructurados), o bien que $\mathrm{F}$ se lleve a cabo de diferente manera a nivel subsistémico en $\mathrm{S} 1$ en comparación con S2 (sólo para el caso de sistemas estructurados), $y$

b. El ancestro común más reciente de $\mathrm{O} 1$ y $\mathrm{O} 2$, O3, tenía un sistema funcional S3 cuya función también era F, del cual S1 y S2 descendieron, quizá con modificaciones. ${ }^{16}$

${ }^{16}$ La cláusula B de esta caracterización de homología funcional distingue la homología funcional del paralelismo funcional, el cual se caracterizaría como sigue (aproximadamente): Los sistemas funcionales $\mathrm{S} 1$ del organismo $\mathrm{O} 1$ y $\mathrm{S} 2$ de $\mathrm{O} 2$ son funcionalmente paralelos sólo si (a) S1 y S2 llevan a cabo la misma función F, quizá de maneras diferentes; (b) el ancestro común más reciente de $\mathrm{Ol}$ y $\mathrm{O} 2$, digamos O3, no tenía un sistema funcional S3 cuya función también era $\mathrm{F}$ y del cual S1 y S2 descendieron; y (c) hay un ancestro común a $\mathrm{Ol}$ y $\mathrm{O} 2$ que tenía un sistema funcional cuya función sí era $\mathrm{F}$ y del cual S1 y S2 descendieron, quizá con modificaciones (este ancestro, por ende, no es el ancestro común más reciente de $\mathrm{O} 1$ y $\mathrm{O} 2$ ). Debemos notar aquí que existe una gran controversia respecto a cómo caracterizar el paralelismo de rasgos morfológicos en contradistinción con la convergencia. Véanse Patterson (1988), Hall (2003 y 2007) y Scotland (2011). 
Procedemos ahora a formular los criterios empíricos de homología funcional que nos permitirán identificar los tipos de evidencia empírica que contarán en favor de una hipótesis de homología funcional. Al igual que con los criterios de homología morfológica, los criterios de homología funcional se agrupan en dos pasos: homología primaria y secundaria. Los criterios de homología primaria también serán tres:

A. Criterio de posición relativa. Tenemos dos sistemas funcionales $\mathrm{S} 1$ y S2 (estructurados o no estructurados). Ambos realizan la función $F$, quizá de otra manera a nivel subsistémico y/o implementacional. El criterio de posición relativa (aplicado a sistemas funcionales) nos dice que hay razón para pensar que estos dos sistemas funcionales $S 1$ y $S 2$ son homólogos cuando son partes funcionales de otros dos sistemas funcionales más amplios, $T 1$ y $T 2$ respectivamente, los cuales llevan a cabo la función $F^{*}\left(F^{*} \neq F\right)$, pero quizá de una manera diferente a nivel subsistémico y/o implementacional. Además, tienen que existir ciertas semejanzas entre $T 1$ y $T 2$ en la forma en que llevan a cabo $F^{*}$ a niveles subsistémico e implementacional, y en la serie temporal de operación de esos subsistemas. Esto es necesario puesto que el criterio nos dice que es precisamente la existencia de tales semejanzas organizacionales (funcionales y morfológicas) entre $T 1$ y $T 2$ lo que nos brinda razones para pensar que $S 1$ y $S 2$ son homólogos -i.e., llevan a cabo la misma función debido a la existencia de un ancestro común. El diagrama de la p. 19 ilustra la idea central de este criterio.

Examinemos ahora un ejemplo de homología funcional y de la forma en que el criterio de posición relativa se aplica en este caso. En la ecología de la conducta, dos formas diferentes de movimiento de la cola en ciertos pájaros se consideran homólogas cuando ocurren en el mismo "lugar" en rituales de cortejo. Las conductas en cuestión -i.e., movimientos de la cola, rituales de cortejo- se caracterizan funcionalmente; ciertamente no se identifican como patrones motores particulares ni como movimientos físicos específicos. Lo que tenemos aquí entonces son dos sistemas funcionales amplios $T 1$ y $T 2$ (ambos caracterizados como rituales de cortejo) y dos subsistemas funcionales $S 1$ y $S 2$ (diferentes movimientos de la cola) que son partes de $T 1$ y $T 2$ respectivamente. Aun cuando los subsistemas funcionales $S 1$ y $S 2$ tienen la misma caracterización funcional (i.e., son movimientos de la cola), no son idénticos; pueden consistir de diferentes patrones 
Criterio de posición relativa

$\mathrm{T} 1$

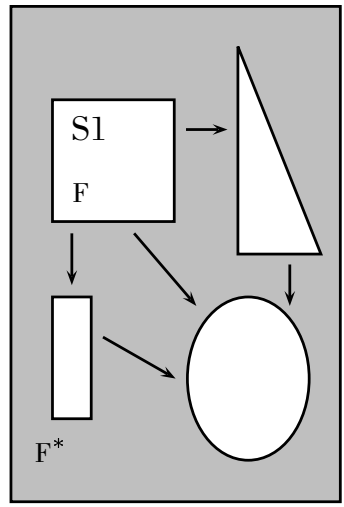

$\mathrm{T} 2$

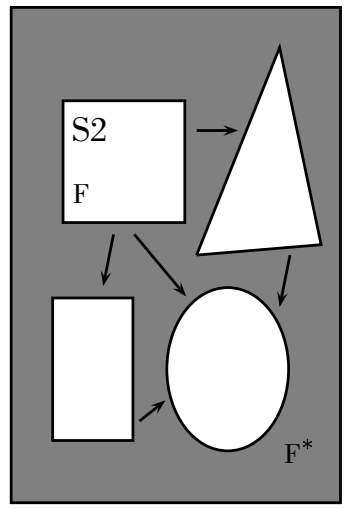

S1 y S2 serán considerados homólogos cuando ambos llevan a cabo la misma función $F$, y son parte de dos subsistemas más amplios. Tl y T2, que llevan a cabo la misma función $F^{*}$ aunque posiblemente de manera diferente. Es crucial que existan, sin embargo ciertas similitudes entre T1 y T2 a nivel subsistémico e implementacional.

Fuente: García 2010.

motores, por ejemplo. $\mathrm{Y}$ algo semejante es posible decir de $T 1 \mathrm{y}$ $T 2$, los rituales de cortejo. El criterio de posición relativa nos dice, entonces, que tenemos evidencia para considerar a $S 1$ y $S 2$ como homólogos cuando son partes de sistemas funcionales más amplios que llevan a cabo la misma función (cortejo de una posible pareja), siempre y cuando $S 1$ y $S 2$ ocurran en el mismo "lugar" en los rituales de cortejo correspondientes, $T 1$ y $T 2$. "El mismo lugar" aquí quiere decir "el mismo lugar en la estructura funcional global de los correspondientes rituales de cortejo". Así, si $S 1$ y $S 2$ están en el mismo lugar en $T 1$ y $T 2$ (respectivamente), entonces, algunas correspondencias estructurales, funcionales y temporales tienen que existir entre $T 1$ y $T 2$. Esto es lo que requiere el criterio de posición relativa. 
1. Criterio de cualidad especial. Este criterio de homología primaria se refiere a la complejidad y/o distintividad de cierto rasgo. Aplicado a sistemas funcionales $S 1$ y $S 2$, el criterio alude o bien a la especificidad de la función que $S 1$ y $S 2$ llevan a cabo, o bien a la complejidad de su operación subsistémica y/o implementacional. En la etología también se usa el criterio de cualidad especial como un criterio para la homología de conductas. Por ejemplo, las diferentes conductas de tejer telarañas de arañas pertenecientes a diferentes taxones son consideradas homólogas puesto que, siendo tan distintivas y tan complejas, es improbable que hayan evolucionado por separado. Además, conductas ritualizadas (como los rituales de apareamiento de pájaros de ciertas especies) se consideran con frecuencia homólogas cuando logran la misma función aun cuando usen diferentes patrones motores (Ereshefsky 2007, p. 665).

2. Criterio de continuidad de Remane: por lo que respecta a sistemas funcionales este criterio se satisface cuando se encuentra un continuo gradual de sistemas funcionales - todos los cuales llevan a cabo una misma función pero de maneras incrementalmente más complejas, ya sea a nivel subsistémico y/o implementacional- En la etología, este criterio también se usa en relación con las conductas y su ontogenia. La idea es que las ontogenias de conductas homólogas se van haciendo más complejas conforme esas conductas van evolucionando (Ereshefsky 2007, p. 665).

Respecto a la homología secundaria, vimos antes que el análisis cladístico constituye el segundo paso para la homología morfológica. La idea es, en consecuencia, construir cladogramas aplicados a los caracteres de los sistemas funcionales (y otros relevantes) usando el método de la parsimonia.

Los detalles de mi propuesta no serán presentados ni defendidos aquí, pero la idea general sobre cómo aplicar todos los criterios anteriores a los sistemas cognitivos se explica en la siguiente tabla: 


\section{DESCRIPCIÓN}

\begin{tabular}{|c|c|c|}
\hline \multicolumn{3}{|l|}{ ESTRUCTURA COGNITIVA } \\
\hline $\begin{array}{l}\text { Identificar los sistemas } \\
\text { cognitivos }\end{array}$ & $S 1$ de organismo $O 1$ & $S 2$ de organismo $O 2$ \\
\hline FUNCIÓN COGNITIVA & $F$ & $F$ \\
\hline $\begin{array}{l}\text { Tipo de sistema cogniti- } \\
\text { vo (computacional): ¿red } \\
\text { neural, sistema clásico, } \\
\text { etcétera? }\end{array}$ & Sí responder la pregunta & Sí responder la pregunta \\
\hline $\begin{array}{l}\text { Subsistemas: ¿los tiene? } \\
\text { ¿qué funciones cognitivas } \\
\text { tienen? ¿cómo } \\
\text { interactúan? }\end{array}$ & Sí responder & Sí responder \\
\hline $\begin{array}{l}\text { Impacto en la conducta: } \\
\text { ¿lo tiene? ¿cómo? ¿qué ti- } \\
\text { pos de conducta?, etcéte- } \\
\text { ra. }\end{array}$ & Sí responder & Sí responder \\
\hline $\begin{array}{l}\text { Insumos y entradas: ¿de } \\
\text { tipos específicos o no? }\end{array}$ & Sí responder & Sí responder \\
\hline $\begin{array}{l}\text { ¿Existen características } \\
\text { especiales de estos } \\
\text { sistemas en algunos de } \\
\text { los rubros anteriores? } \\
\text { ¿cuáles? (cualidad } \\
\text { especial) }\end{array}$ & Sí responder & Sí responder \\
\hline \multicolumn{3}{|l|}{$\begin{array}{l}\text { POSICIÓN EN LA } \\
\text { ARQUITECTURA } \\
\text { COGNITIVA GLOBAL } \\
\text { (posición relativa) }\end{array}$} \\
\hline & $\begin{array}{l}\text { ¿Con qué otros sistemas } \\
\text { de organismo } O 1 \text { ser re- } \\
\text { laciona (directa o indi- } \\
\text { rectamente) } S 1 \text { ? } \\
\text { ¿Qué otros sistemas de } \\
O 1 \text { le proporcionan el } \\
\text { insumo a } S 1 \text { ? } \\
\text { ¿A que otros sistemas de } \\
O 1 \text { le proporciona insu- } \\
\text { mos } S 1 \text { ? }\end{array}$ & $\begin{array}{l}\text { ¿Con qué otros sistemas } \\
\text { de } O 2 \text { ser relaciona (di- } \\
\text { recta o indirectamente) } \\
S 2 \text { ? } \\
\text { ¿Qué otros sistemas de } \\
O 2 \text { le proporcionan el } \\
\text { insumo a } S 2 \text { ? } \\
\text { ¿A qué otros sistemas de } \\
O 2 \text { le proporciona insu- } \\
\text { mos } S 2 \text { ? }\end{array}$ \\
\hline
\end{tabular}




\begin{tabular}{|l|l|l|}
\hline $\begin{array}{l}\text { DESARROLlO } \\
\text { COGNITIVO } \\
\text { ONTOGENÉtico }\end{array}$ & \\
\hline \multirow{4}{\text{(Cualidadespecial)}}{} & $\begin{array}{l}\text { ¿Existe un periodo sen- } \\
\text { sible en el desarrollo tí- } \\
\text { pico de } S 1 \text { en } O 1 ? \\
\text { ¿Existen características } \\
\text { especiales del desarrollo } \\
\text { de } S 1 \text { en } O 1 ?\end{array}$ & $\begin{array}{l}\text { ¿Eible un periodo sen- } \\
\text { pico de } S 2 \text { en } O 2 ? \\
\text { ¿Existen características } \\
\text { especiales del desarrollo } \\
\text { de } S 2 \text { en } O 2 ?\end{array}$ \\
\hline \hline
\end{tabular}

ESTRUCTURA NEUROCEREBRAL

\begin{tabular}{|c|c|c|}
\hline $\begin{array}{l}\text { IDENTIFICAR LAS } \\
\text { ESTRUCTURAS } \\
\text { NEURONALES QUE } \\
\text { TÍPICAMENTE } \\
\text { IMPLEMENTAN LA } \\
\text { FUNCIÓN COGNITIVA F }\end{array}$ & Sí & Sí \\
\hline (¿Cualidad especial?) & $\begin{array}{l}\text { ¿Hay regiones cerebrales } \\
\text { de } O 1 \text { que preferencial- } \\
\text { mente llevan a cabo } F \text { ? } \\
\text { ¿Son las neuronas en es- } \\
\text { tas regiones funcional- } \\
\text { mente específicas para } \\
F \text {, o no? }\end{array}$ & $\begin{array}{l}\text { ¿Hay regiones cerebrales } \\
\text { de } O 2 \text { que preferencial- } \\
\text { mente llevan a cabo } F ? \\
\text { ¿Son las neuronas en } \\
\text { estas regiones funcio- } \\
\text { nalmente específicas } \\
\text { para } F ?\end{array}$ \\
\hline (¿Cualidad especial?) & $\begin{array}{l}\text { ¿Cuáles son las caracte- } \\
\text { rísticas citoarquitectóni- } \\
\text { cas de estas regiones? }\end{array}$ & $\begin{array}{l}\text { ¿Cuáles son las caracte- } \\
\text { rísticas citoarquitectóni- } \\
\text { cas de estas regiones? }\end{array}$ \\
\hline & $\begin{array}{l}\text { ¿Qué regiones o grupos } \\
\text { particulares de células } \\
\text { implementan los subsis- } \\
\text { temas cognitivos de } S 1 \text { ? }\end{array}$ & $\begin{array}{l}\text { ¿Qué regiones o grupos } \\
\text { particulares de células } \\
\text { implementan los subsis- } \\
\text { temas cognitivos de } S 2 \text { ? }\end{array}$ \\
\hline (Posición relativa) & $\begin{array}{l}\text { ¿Cuál es la localización } \\
\text { topológica (y topográfi- } \\
\text { ca) de estas regiones en } \\
\text { el cerebro de } O l \text { ? }\end{array}$ & $\begin{array}{l}\text { ¿Cuál es la localización } \\
\text { topológica (y topográfi- } \\
\text { ca) de estas regiones en } \\
\text { el cerebro de O2?* }\end{array}$ \\
\hline & $\begin{array}{l}\text { ¿Qué regiones cerebra- } \\
\text { les de Ol implementan } \\
\text { los otros sistemas cogni- } \\
\text { tivos de } O 1 \text { con los que } \\
\text { interactúa } S l \text { ? }\end{array}$ & $\begin{array}{l}\text { ¿Qué regiones cerebra- } \\
\text { les de } O 2 \text { implementan } \\
\text { los otros sistemas cogni- } \\
\text { tivos con los que inter- } \\
\text { actúa } S 2 \text { ? }\end{array}$ \\
\hline
\end{tabular}

* Véase Nieuwenhuys et al. (1996), especialmente el cap. 6, quien explica en detalle la diferencia entre posición topológica y topográfica en el contexto de las neurociencias comparadas. 


\section{HOMOLOGÍA U HOMOPLASIA}

\begin{tabular}{|c|c|}
\hline \multicolumn{2}{|c|}{ HOMOLOGÍAS PRIMARIAS } \\
\hline \multicolumn{2}{|c|}{$\begin{array}{l}\text { Homología primaria a } \\
\text { nivel cognitivo }\end{array}$} \\
\hline Cualidad especial & $\begin{array}{l}\text { Comparar las características cognitivas que puedan } \\
\text { ser especiales de } S 1 \text { y } S 2 \text { : ¿son diferentes, muy pa- } \\
\text { recidas o las mismas? }\end{array}$ \\
\hline Posición relativa & 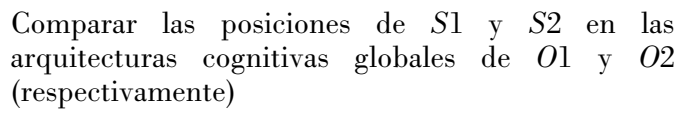 \\
\hline Continuidad & $\begin{array}{l}\text { Comparar todas las características cognitivas de } S 1 \\
\text { y } S 2 \text {, y determinar si la mayoría de ellas son muy } \\
\text { parecidas o iguales }\end{array}$ \\
\hline \multicolumn{2}{|c|}{$\begin{array}{l}\text { Homología primaria a ni- } \\
\text { vel neurocerebral }\end{array}$} \\
\hline Cualidad especial & $\begin{array}{l}\text { Comparar las características neurocerebrales que } \\
\text { puedan ser especiales de } S 1 \text { y } S 2\end{array}$ \\
\hline Posición relativa & $\begin{array}{l}\text { Comparar las localizaciones (principalmente las to- } \\
\text { pológicas) de las regiones o grupos neuronales de } O 1 \\
\text { y } O 2 \text { que implementan } S 1 \text { y } S 2 \text { (respectivamente) }\end{array}$ \\
\hline Continuidad & $\begin{array}{l}\text { Comparar todas las características neurocerebrales } \\
\text { de las regiones de } O 1 \text { y } O 2 \text { que implementan a } S 1 \\
\text { y } S 2 \text {, y determinar si la mayoría de ellas son muy } \\
\text { parecidas o iguales }\end{array}$ \\
\hline \multicolumn{2}{|c|}{ HOMOLOGÍAS SECUNDARIAS } \\
\hline Nivel cognitivo & $\begin{array}{l}\text { Construir el cladograma más parsimonioso aplicado } \\
\text { a los caracteres cognitivos de } S 1 \text { y } S 2\end{array}$ \\
\hline Nivel neurocerebral & $\begin{array}{l}\text { Construir el cladograma más parsimonioso aplica- } \\
\text { do a los caracteres neurocerebrales de las regiones } \\
\text { cerebrales o grupos celulares de } O 1 \text { y } O 2 \text { que im- } \\
\text { plementan a } S 1 \text { y } S 2 \text { (respectivamente) }\end{array}$ \\
\hline \multirow[t]{2}{*}{ PASO FINAL } & $\begin{array}{l}\text { Si los dos cladogramas resultantes coinciden, enton- } \\
\text { ces esto constituye evidencia adicional a favor de las } \\
\text { hipótesis de homología a nivel cognitivo }\end{array}$ \\
\hline & $\begin{array}{l}\text { Si no coinciden, esto puede constituir una razón } \\
\text { para disminuir el grado de credibilidad que se le } \\
\text { asigne a tales hipótesis }\end{array}$ \\
\hline
\end{tabular}

${ }^{\dagger}$ Striedter (2006) explica muy claramente los criterios para determinar hipótesis de homología primaria en la neurología comparada. 
Aquí no ilustraré la forma en la cual mi propuesta podría ser aplicada en casos particulares - esto es algo que he empezado a hacer en otra parte respecto del sistema cognitivo de reconocimiento de caras en primates humanos y no humanos-. ${ }^{17}$ Lo que sí haré es examinar cuál es la manera adecuada de entender la noción de función en el contexto de la conceptualización y la determinación de homologías, tanto morfológicas como funcionales, y explicar por qué ésta es una pregunta muy importante.

\section{Conceptos de función en la filosofía de la biología y de las ciencias cognitivas}

Existe una gran discusión entre biólogos, filósofos de la biología y de las ciencias cognitivas en relación con las siguientes cuestiones: (a) si existe sólo un concepto de función en la biología y en las ciencias cognitivas; (b) cuál o cuáles son las mejores explicaciones de la naturaleza de estos conceptos; (c) si las explicaciones propuestas de tales conceptos son descripciones o revisiones del significado de la palabra "función" tal y como ésta se usa en la biología y/o en las ciencias cognitivas; o si más bien son prescripciones acerca de la forma en la cual la palabra debería ser usada; y (d) si la respuesta correcta a estas preguntas tiene que basarse únicamente en el análisis conceptual o si también podría hacer uso de consideraciones empíricas, etc. (Millikan 2002, p. 114; Cummins 1975, p. 76.)

El único consenso que parece existir entre los filósofos con respecto a la noción de función es que existen dos grandes clases de conceptos de función que se usan (o deberían usarse) en la biología y en las ciencias cognitivas: los llamados "conceptos Cummins" (o analítico-sistémicos "systems analysis"), y los conceptos etiológicos. ${ }^{18}$ Examinemos brevemente cada una de estas clases, empezando por los conceptos analítico-sistémicos.

En 1975, Robert Cummins propuso caracterizar el concepto de función de la siguiente manera: sea $s_{j}(j=1, \ldots, n)$ un subsistema de un sistema más amplio $s$; entonces,

La función de $s_{j}$ en $s$ es llevar a cabo $f_{j}$ (relativo a una explicación analítica $\mathrm{C}$ de la capacidad de $s$ para hacer $F$ ) precisamente cuando

${ }^{17}$ Véase García 2013.

${ }^{18}$ Millikan (2002) habla de éstos como "dos paradigmas respecto a las funciones biológicas". Sin embargo, Paul Sheldon Davies (2000) intenta mostrar que el concepto etiológico-seleccionista de función no es sino una instancia del concepto analítico-sistémico. Por limitaciones de espacio, aquí no podré entrar en los detalles de su argumento ni en las razones por las que pienso que no está en lo correcto. 
$s_{j}$ tiene la capacidad de llevar a cabo $f_{j}$ en s y $C$ explica de manera apropiada y adecuada la capacidad de $S$ para hacer $F$ en parte apelando a la capacidad de $s_{j}$ para llevar a cabo $f_{j}$ en $s$. (Cummins 1975, p. 762)

Así, en el sentido de Cummins, cuando la capacidad de un sistema $s$ más amplio para hacer $F$ se explica en parte apelando a la capacidad de su subsistema $s_{j}$ para llevar a cabo $f_{j}$, entonces se dice que $f_{j}$ es una función de $s_{j}$. Cummins estaba tratando de capturar una noción de función que fuese útil en aquellas disciplinas en las que ésta estuviera relacionada con explicaciones funcionales —es decir, explicaciones en las cuales la capacidad de un sistema complejo para hacer algo fuera explicada en términos de las funciones de sus partes constitutivas-.

Nótese que para Cummins las funciones son capacidades que ciertos (sub)sistemas tienen para hacer ciertas cosas de ciertas maneras y en ciertas condiciones. Una de las ventajas de su propuesta es que captura la manera en la cual fisiólogos y morfólogos funcionales hablan acerca de las funciones de determinados órganos y, más aún, la forma en la cual la mayoría de los psicólogos cognitivos hablan de funciones psicológicas. ${ }^{19}$

Por otra parte, con respecto a los conceptos etiológicos de función, Ruth Millikan (1984) fue de los primeros en proponer una caracterización de la noción de función de este tipo. De hecho, su teoría es de un tipo más particular: la "teoría etiológico-seleccionista". De acuerdo con el modo en que concibe la noción de función (que ella llama "función propia"), la

función de un miembro $X$ de una familia reproductivamente establecida es hacer $\mathrm{Y}$ precisamente cuando los ancestros de $X$ hacían $Y$ y el hecho de que hacían $Y$ contribuyó causalmente a un mayor éxito reproductivo de su familia en comparación con el de las familias reproductivamente establecidas competidoras. (Buller 1999, p. 17) ${ }^{20}$

Millikan caracteriza de forma amplia a los conceptos centrales que aparecen en esta noción de función — conceptos tales como los de "familias reproductivamente establecidas", "ancestros", "éxito reproductivo", etc. - de manera que puedan ser aplicados no sólo a entidades biológicas sino también a otros tipos apropiados de entidades.

${ }^{19}$ Cummins propuso su noción de función precisamente para capturar una noción de función psicológica en uso en la psicología cognitiva.

${ }^{20}$ Empleo aquí la caracterización de Buller de la posición de Millikan pues me parece más compacta, sin sacrificar la claridad, que las que ella ofrece. 
Si se comparan la noción de función de Cummins, las funciones en Millikan no son capacidades de ningún tipo. De hecho, según ella, algo puede tener una función $F$ y no tener la capacidad de hacer $F$. Por ejemplo, un corazón malformado puede tener la función de bombear sangre aun si en la actualidad no tiene esa capacidad. Sólo es necesario que ese corazón tenga la historia evolutiva apropiada; es decir, sólo es necesario que los ancestros de ese organismo tuvieran corazones que bombearan sangre de una manera específica y que el que lo hicieran les hubiese conferido un mayor éxito reproductivo. De hecho, se dice que un corazón está "malformado" porque no puede bombear sangre (o lo hace mal) aunque su función siga siendo la de bombear sangre. Millikan señala esta consecuencia como una ventaja de su propuesta. ${ }^{21}$ Cummins, por su parte, no parece tener herramientas semejantes para conceptualizar a las disfunciones - es decir, para articular en términos conceptuales la idea de que algo puede tener una función que no puede llevar a cabo (o que no puede hacerlo apropiadamente)-.

Desarrollos posteriores intentaron evitar algunas de las objeciones que en un principio se les presentaron a estas teorías. Por ejemplo, en muchos casos parece contraintuitivo pensar que sea posible que toda una población de cierta especie tenga un órgano $O$ cuya función es la de hacer $F$ sin que ninguno de los órganos $O$ de los miembros de esa población tenga la capacidad de hacer $F$ - una posibilidad que la explicación de Millikan deja abierta-. Bigelow y Pargetter (1987) hacen entonces una propuesta semejante a la de Millikan (en el sentido de ser etiológico-seleccionista) que no deja abierta esta posibilidad; según ellos, un rasgo de los organismos de una población $P$ tiene una función $F$ cuando el que ese rasgo tenga la capacidad de hacer $F$ (en los organismos de $P$ en los que la tiene) incrementa la adecuación (fitness) de esos organismos - es decir, incrementa sus probabilidades de éxito reproductivo - . Claramente, de acuerdo con esta caracterización de la noción de función, no es posible que toda una población de cierta especie tenga un órgano $O$ cuya función es la de hacer $F$ sin que ninguno de los órganos $O$ de los miembros de esa población tenga actualmente la capacidad de hacer $F$.

Respecto a las teorías analítico-sistémicas como la de Cummins, varios autores han intentado responder a la objeción de que teorías de este tipo no pueden conceptualizar a las disfunciones. La idea es que si, según estas teorías, $X$ tiene la función de hacer $F$ sólo si $X$

${ }^{21}$ Véase también a Neander (1995), quien ahonda sobre esta posibilidad de hablar de disfunciones en la teoría etiológica seleccionista. 
tiene la capacidad de hacer $F$, entonces no es posible que algo tenga una función y que no tenga la capacidad de llevarla a cabo -i.e., no es posible que existan las disfunciones-.

Sin embargo, no estoy segura de qué tan seria es esta objeción. La noción de disfunción parece ser de suma importancia para entender algunas nociones (como la de enfermedad) que se manejan en la medicina, incluyendo a la psiquiatría. Lo que no es evidente es que esta noción sea del todo importante - o incluso necesaria - en la biología y en las ciencias cognitivas. Para empezar, la mayoría de los biólogos evolutivos piensan que no la requieren; ellos hablan de variaciones genéticas y fenotípicas que tienen diferentes grados de adecuación, incluso de variaciones letales, pero la noción de enfermedad no entra en estas descripciones.

Otra objeción a una teoría como la de Cummins — más seria en este contexto y relacionada con la anterior a un nivel más profundodescansa en la sospecha de que no existen maneras "objetivas" e independientes de los intereses explicativos de los investigadores relevantes, de individuar sistemas funcionales - en particular, que las maneras en las que se escogen los factores causales que sí, y los que no, forman parte de un sistema determinado están inextricablemente ligadas a un gran número de consideraciones heterogéneas que definen qué es una buena explicación en un cierto contexto disciplinario y teórico, qué es lo que se quiere explicar, a quién va dirigida la explicación, etc. Millikan no tiene este problema (si lo es) porque su noción de función no se aplica a sistemas de manera especial, sino también a muchos otros tipos de entidades. ${ }^{22}$ La propuesta de Cummins, por otra parte, sí hace uso de la noción de sistema de forma ineludible.

La objeción anterior, sin embargo, debe toda su fuerza al supuesto de que, en razón de que nuestra postulación de la existencia de un determinado sistema se justifica respecto de nuestras necesidades explicativas en un cierto contexto (y dado que la forma que toma una explicación satisfactoria puede cambiar de un contexto a otro), se sigue que el sistema en cuestión tiene sólo una existencia relativa - que no tiene ningún sentido decir que el sistema "existe" de manera independiente de esas necesidades y de nuestras concepciones de lo que es una buena explicación-. Pero este supuesto no es inevitable, aparte de ser controversial. Alguien podría defender un realismo de sistemas, diciendo que en ciertos casos los sistemas postulados

\footnotetext{
${ }^{22}$ Lo mismo puede decirse de la caracterización de función de Bigelow y Pargetter
} (1987). 
realmente existen de manera absoluta (es decir, independiente), y construyendo una teoría que enuncie algunas condiciones plausibles en las cuales sí se puede suponer que ciertos sistemas funcionales existen en un sentido absoluto. Aquí no quiero sugerir que esta postura sea más plausible que su contraria; lo único que pretendo resaltar es que alguien podría defender un realismo de sistemas funcionales y al mismo tiempo adoptar una caracterización de las funciones como la de Cummins - en cuyo caso, hablar de funciones en este sentido no tendría como consecuencia necesaria un relativismo funcional- .

Finalmente, debemos notar que la mayoría de los filósofos de la biología y de las ciencias cognitivas aceptan un pluralismo respecto de los conceptos de función; es decir, aceptan que, en algunas disciplinas científicas, el concepto de función que está en uso es de un tipo etiológico, mientras que en otras la palabra "función" se use más en un sentido sistemático (Godfrey-Smith 1993). ${ }^{23}$ Con todo, algunos teóricos intentan argumentar la idea de que los conceptos etiológico y analítico-sistémico son, en el fondo, dos formas de una misma idea (Kitcher 1993), mientras que otros se aventuran a defender un monismo funcional según el cual ambos conceptos son claramente distintos aunque de hecho sólo uno de ellos está en uso (o debería usarse) en la biología y en las ciencias cognitivas (Neander 1991). De nuevo, aquí no voy intentar dilucidar cuál de estas posiciones es la más adecuada - para mis propósitos, esto no es necesario-. Más bien me preguntaré cuál de los dos conceptos de función antes examinados se ajusta (más) naturalmente a la idea que subyace al concepto de homología funcional. ${ }^{24}$

\section{Homología y función}

En esta sección argumento que el concepto de función analíticosistémico es el que encaja de manera más coherente con el de homología funcional que aquí propongo. Además, enuncio las razones por las cuales los conceptos etiológico-seleccionistas de función no encajan de igual manera con aquél, aunque por lo menos uno de ellos no es lógicamente contradictorio con la noción de homología funcional. Recordemos cómo propuse caracterizar la homología funcional (supra, p. 17):

${ }^{23}$ Adicionalmente, Paul Sheldon Davies (2000) intenta mostrar que el concepto etiológico-seleccionista de función no es sino una instancia del concepto analíticosistémico. Por limitaciones de espacio, aquí no podré entrar en los detalles de su argumento ni en las razones por las que pienso que no está en lo correcto.

${ }^{24}$ Discusiones más recientes alrededor del concepto de función en biología y psicología se encuentran en Ariew et al. 2002. 
Sistemas funcionales $\mathrm{S} 1$ del organismo $\mathrm{O} 1$ y $\mathrm{S} 2$ de $\mathrm{O} 2$ son funcionalmente homólogos cuando:

a. S1 y S2 pueden llevar a cabo la misma función $\mathrm{F}$, quizá de una manera distinta, ya sea que $\mathrm{F}$ se implemente de manera diferente en $\mathrm{S} 1$ y $\mathrm{S} 2$ (en el caso tanto de sistemas estructurados como no estructurados), o bien que $\mathrm{F}$ se lleve a cabo de diferente manera a nivel subsistémico en $\mathrm{Sl}$ en comparación con $\mathrm{S} 2$ (sólo para el caso de sistemas estructurados), $y$

b. El ancestro común más reciente de $\mathrm{O} 1$ y $\mathrm{O} 2$, O3, tenía un sistema funcional S3 cuya función también era $\mathrm{F}$, del cual S1 y S2 descendieron, quizá con modificaciones.

La cláusula (a) de esta caracterización requiere que dos sistemas funcionalmente homólogos puedan llevar a cabo la misma función $F$, aunque quizá de diferente manera. Esto implica que la caracterización de homología funcional requiere que dos sistemas homólogos tengan la capacidad de llevar a cabo esa función. Y, como ya mencioné, de acuerdo con la noción millikeana de función, un rasgo puede tener la función $F$ sin tener la capacidad de llevar a cabo $F$ - como en el caso de un corazón disfuncional-. Así, la noción de función que aparece en la caracterización anterior de homología funcional no puede ser la de Millikan. Pero quizá sí podría ser la noción de Bigelow y Pargetter, según la cual un rasgo de los organismos de una población $P$ tiene una función $F$ cuando el hecho de que ese rasgo tenga la capacidad de hacer $F$ (en los organismos de $P$ en los que la tiene) incrementa la adecuación (fitness) de esos organismos - es decir, incrementa sus probabilidades de éxito reproductivo-.

De acuerdo con esta nueva caracterización de función, las funciones sí son capacidades. ${ }^{25} \mathrm{Y}$ esto es justo lo que me parece correcto de la propuesta de estos autores, mas lo que me parece cuestionable - en el contexto de la intuición que subyace a la noción de homología funcional que aquí propongo- es que rasgos de un organismo puedan tener funciones sin necesidad de estar inmersos en estructuras sistémicas más amplias que los encapsulen. Veamos.

Según los criterios empíricos asociados al concepto de homología funcional que propongo, las relaciones cognitivas funcionales que

${ }^{25}$ De hecho, ellos prefieren hablar de "propensiones" y no de capacidades - aunque para nuestros propósitos la diferencia no es relevante, ya que ambas cosas son entidades disposicionales- (Bigelow y Pargetter 1987). 
dos sistemas cognitivos de dos organismos tienen con otros sistemas cognitivos de esos organismos, y el orden temporal de su interacción - para usar una metáfora muy usada y muy útil, la "posición" que esos sistemas tienen en la arquitectura cognitiva (y neural) global de cada uno de esos organismos - son cruciales para determinar tanto la homología primaria como la secundaria: en la primaria, está el criterio de posición relativa; en la secundaria, los caracteres concernientes a las relaciones en cuestión entran en la construcción de los cladogramas correspondientes. Esto quiere decir que el anclaje empírico de la noción misma de homología funcional hace una referencia crucial a la idea de que una función es algo que está inmerso en un sistema más amplio - es decir, a la idea básica que subyace a una noción sistémica de función como la de Cummins-.

Por otra parte, la idea de que una función es algo que confirió (Millikan) o confiere (Bigelow y Pargetter) una ventaja adaptativa a un grupo de organismos es irrelevante en el contexto de la conceptualización y determinación empírica de la homología funcional: decir que dos rasgos son homólogos - esto es, que descendieron con modificaciones de un ancestro común - no dice nada acerca de los mecanismos evolutivos que intervinieron en ese proceso de descendencia y de modificación. Dos rasgos pueden ser homólogos aún cuando lo que explica su continuidad en los linajes correspondientes sea, por ejemplo, la existencia de constreñimientos físicos, mientras que lo que explica los cambios que han ido experimentando no es la selección natural sino la deriva genética. Paralelamente, decir que dos rasgos en dos linajes no son homólogos sino convergentes tampoco implica nada acerca de los mecanismos evolutivos que intervinieron en la aparición inicial de tales rasgos en los linajes mencionados. La selección natural es un mecanismo evolutivo; uno muy importante, pero no el único, y otros mecanismos - por ejemplo, la deriva genética, la exaptación, los constreñimientos físicos, funcionales y los del desarrollo - también juegan un papel en la evolución. Qué tan central es este papel, es justo lo que está en discusión en la actualidad en el contexto de la llamada "EvoDevo". El punto aquí es simplemente que las cuestiones en torno a la homología - tanto morfológica como funcional- son ortogonales a las discusiones relativas a los mecanismos de la evolución, y sus importancias relativas. Como afirma Paul Griffiths: "simplemente no es verdad que las etapas prominentes en la secuencia de transformación [establecida por el cladograma más parsimonioso] son definidas por los cambios en las presiones de selección de un carácter" (Griffiths 2006, p. 14). 
Por otra parte, las teorías etiológico-seleccionistas sobre funciones en la biología tienen como consecuencia que un rasgo de organismos de una población $P$ no puede tener una determinada función $F$ a menos que el hecho de que ese rasgo pueda llevar a cabo $F$ en los miembros (o en algunos de los ancestros) de $P$ incremente la probabilidad de una reproducción exitosa de esos organismos (o de sus ancestros) - en otras palabras, incrementa la probabilidad que esos organismos sean (o hayan sido) seleccionados naturalmente-. Así, estos conceptos de función están comprometidos de inicio con la idea de que la selección natural existe y es constitutiva de la existencia de las funciones. Por otra parte, aceptar el concepto de homología funcional que yo propongo no tiene ningún compromiso como éste.

Todo lo anterior no implica que el concepto de homología funcional (junto con sus criterios empíricos) no se pueda aplicar a aquellos sistemas funcionales en los cuales la noción de función involucrada sea la etiológico-seleccionista propuesta por Bigelow y Pargetter. Tiene que ser el caso, en el cual el sistema funcional caracterizado en términos de una función etiológico-seleccionista como la que ellos proponen, se encuentre inmerso dentro de un sistema funcional más amplio, en cuya operación aquél hace una contribución funcional.

Por último, podría objetarse que existe una circularidad en mi argumentación al proponer de entrada una noción de sistema funcional que supuestamente es muy afín a la noción cumminseana de función. Sin embargo, la noción de sistema funcional que uso al caracterizar la homología funcional es la que, desde mi punto de vista, opera en la psicología cognitiva. Es además una noción mínima que supone únicamente que un sistema funcional es una entidad que se individúa de manera primordial por alguna de sus funciones y no por otras de sus características tales como su implementación en el cerebro o en alguna otra parte de un organismo - y no supone que esta función tenga que ser millikeana o cumminseana-. Asimismo, desde mi punto de vista, un sistema funcional no necesariamente está compuesto por subsistemas funcionales —algo que Cummins sí requiere en su caracterización de función-. No obstante, insatisfecho con esta respuesta, alguien podría pensar que algunos de los criterios de homología primaria llamados de "posición relativa" presuponen que los sistemas funcionales cuya homología (u homoplasia) se está intentando determinar están subsumidos (o son partes funcionales de) en sistemas funcionales más amplios al funcionamiento de los cuales aquéllos contribuyen funcionalmente - lo cual parecería que implica presuponer que los sistemas funcionales en cuestión son cumminseanos-. Pero esto es falso, lo único que esto implica, 
es que los sistemas funcionales que no estén inmersos en contextos funcionales más amplios no podrán ser evaluados — respecto de homología/homoplasia - usando el criterio de posición relativa (presentado en la sección 3 del presente ensayo), pero no se sigue que no podrían ser evaluados por los otros criterios de homología primaria - el de cualidad especial y el de continuidad - y mucho menos se sigue que no podría evaluarse usando un análisis cladístico.

\section{Conclusiones}

Aquí presenté brevemente mi propuesta de un concepto de homología funcional que es aplicable a sistemas funcionales - por ejemplo, a sistemas cognitivos - es decir, a entidades caracterizables primordialmente en términos de por lo menos una de sus funciones. También expuse los criterios empíricos asociados a este concepto; los cuales son claros y suficientemente semejantes a los criterios empíricos de homología morfológica que ya son muy aceptados. Después argumenté que el concepto de función que encaja de manera más coherente con mi concepto de homología funcional y sus criterios empíricos es el analítico-sistémico, propuesto en un principio por Robert Cummins. Esto me parece una buena razón para pensar que el concepto analítico-sistémico de función es, en cualquier caso, indispensable en la construcción de una teoría evolutiva de las capacidades cognitivas de los animales y, en particular, de los humanos.*

\section{BIBLIOGRAFÍA}

Abouheif, E., 1999, "Establishing Homology Criteria for Regulatory Gene Networks: Prospects and Challenges", Homology, Wiley (Novartis Foundation Symposium 222), Chichester, pp. 207-225.

- 1997, "Developmental Genetics and Homology: A Hierarchical Approach", TREE, vol. 12, no. 10, pp. 405-408.

Allen, C., 2004, "Is Anyone a Cognitive Ethologist?", Biology and Philosophy, vol. 19, pp. 589-607.

*Agradezco a los dictaminadores anónimos de este ensayo por sus interesantes comentarios y sugerencias. Gracias también para los miembros del proyecto de investigación titulado "Representación y cognición" — especialmente, Axel Barceló, Angeles Eraña y Kirareset Barrera - y para los miembros del seminario de investigación titulado "Biología y filosofía", en particular, para Carlos López Beltrán, Fabrizzio Guerrero Mc Manus y Francisco Vergara Silva. Todos ellos hicieron valiosos comentarios a diferentes versiones del presente ensayo. Las traducciones al castellano de textos originalmente en inglés son mías. 
Allen, C., 1992, "Mental Content and Evolutionary Explanation", Biology and Philosophy, vol. 7, no. 1, pp. 1-12.

Allen, C. y M. Bekoff, 1995, "Cognitive Ethology and the Intentionality of Animal Behavior", Mind and Language, vol. 10, no. 4, pp. 313-328.

Agnarsson, I. y J.A. Coddington, 2008, "Quantitative Tests of Primary Homology", Cladistics, vol. 24, no. 1, pp. 51-61.

Ariew, A., R. Cummins y M. Perlman (comps.), 2002, Functions: New Essays in the Philosophy of Psychology and Biology, Oxford University Press, Oxford.

Beer, C.G., 1991, "From Folk Psychology to Cognitive Ethology", en C.A. Ristau (comp.), Cognitive Ethology: The Minds of Other Animals, Lawrence Erlbaum Associates, Hillsdale, Nueva Jersey, pp. 19-34.

Benjamin, S.P. y S. Zschokke, 2004, "Homology, Behaviour and Spider Webs: Web Construction Behaviour of Linyphiahortensis and L. triangularis (Araneae: Linyphiidae) and Its Evolutionary Significance", Journal of Evolutionary Biology, vol. 17, no. 1, pp. 120-130.

Bigelow, J. y R. Pargetter, 1987, "Functions", The Journal of Philosophy, vol. 84, pp. 181-196.

Bosch, J., Y. Maeta, y R. Rust, 2001, “A Phylogenetic Analysis of Nesting Behavior in the Genus Osmia (Hymenoptera: Megachilidae)", Annals of the Entomological Society of America, vol. 94, no. 4, pp. 617-627.

Brower, A.V.Z. y V. Schawaroch, 1996, "Three Steps of Homology Assessment", Cladistics, vol. 12, no. 3, pp. 265-272.

Buller, D.J., 1999, Function, Selection, and Design, SUNY Press, Series in Philosophy and Biology, Albany.

Butler, A. y W.M. Saidel, 2000, "Defining Sameness: Historical, Biological, and Generative Homology", BioEssays, vol. 22, no. 9, pp. 846-853.

Craver, C., 2001, "Role Functions, Mechanisms, and Hierarchy", Philosophy of Science, vol. 68, no. 1, pp. 53-74.

Cummins, R., 1975, "Functional Analysis", The Journal of Philosophy, vol. 72, no. 20, pp. 741-765.

Davies, P.S., 2000, "The Nature of Natural Norms: Why Selected Functions are Systemic Capacity Functions", NOÛS, vol. 34, no. 1, pp. 85-107.

de Pinna, M.G.G., 1991, "Concepts and Tests of Homology in the Cladistic Paradigm", Cladistics, vol. 7, no. 4, pp. 367-394.

de Queiroz, A. y P.H. Wimberger, 1993, "The Usefulness of Behavior for Phylogeny Estimation: Levels of Homoplasy in Behavioral and Morphological Characters", Evolution, vol. 47, no. 1, pp. 46-60.

Ereshefsky, M., 2007, "Psychological Categories as Homologies: Lessons from Ethology", Biology and Philosophy, vol. 22, no. 5, pp. 659-674.

Farris, J.S., 2011, "Systemic Foundering", Cladistics, vol. 27, no. 2, pp. 207-221.

Fitch, W.M., 1971, “Toward Defining the Course of Evolution: Minimum Change for a Specific Tree Topology", Systematic Biology, vol. 20, no. 4, pp. 406-416. 
Futuyma, D., 1998, Evolutionary Biology, Sinauer Associates, Sunderland, Mass.

García, C.L., 2013, "La homología de sistemas cognitivos: el caso del reconocimiento de caras en primates humanos y no humanos", en J. González y P. King (comps.), Ciencias cognitivas: entre la cooperación y la integración, UAQ/Editorial Porrúa, México.

,- 2010 , "Functional Homology and Functional Variation in Evolutionary Cognitive Science", Biological Theory, vol. 5, no. 2, pp. 124-135.

Griffiths, P.E., 2006, "Function, Homology and Character Individuation", Philosophy of Science, vol. 73, no. 1, pp. 1-25.

Godfrey-Smith, P., 1993, "Functions: Consensus without Unity", Pacific Philosophical Quarterly, vol. 74, no. 3, pp. 196-208.

Hall, B.K., 2007, "Homoplasy and Homology: Dichotomy or Continuum?", Journal of Human Evolution, vol. 52, pp. 473-479.

, 2003, "Descent with Modification: The Unity Underlying Homology and Homoplasy as Seen Through an Analysis of Development and Evolution", Biological Reviews of the Cambridge Philosophical Society, vol. 78, no. 3, pp. 409-433.

Hawkins, J.A., C.E. Hughes y R.W. Scotland, 1997, "Primary Homology Assessment, Characters and Character States", Cladistics, vol. 13, no. 3 pp. 275-283.

Hennig, W., 1950, Grundzügeeiner Theorie der Phylogenetischen Systematik, Deutscher Zentral verlag, Berlín.

Heyes, C. y A. Dickinson, 1990, "The Intentionality of Animal Action", Mind and Language, vol. 5, no. 1, pp. 87-104.

Jardine, N., 1969, "The Observational and Theoretical Components of Homology: A Study on the Morphology of the Dermal Skull-Roofs of Rhipidistian Fishes", Biological Journal of the Linnean Society, vol. 1, no. 4, pp. 327-361.

Kitcher, P., 1993, "Function and Design", in Midwest Studies in Philosophy, vol. 18, no. 1, pp. 379-397.

Kluge, A., 1993, “Three Taxon Transformation in Phylogenetic Inference: Ambiguity and Distortion as Regards Explanatory Power", Cladistics, vol. 9, no. 2, pp. 246-259.

Kluge, A. y J.S. Farris, 1970, "A Numerical Approach to Phylogenetic Systematics", Systematic Zoology, vol. 19, no. 2, pp. 172-189.

Laubichler, M.D., 2000, "Homology in Development and the Development of the Homology Concept", American Zoologist, vol. 40, no. 5, pp. 777788.

Lee, P.L.M., D.H. Clayton, R. Griffiths, y R.D.M. Page, 1996, "Does Behavior Reflect Phylogeny in Swiftlets (Aves: Apodidae)? A Test Using Cytochrome $b$ Mitochondrial DNA Sequences", Proceedings of the National Academy of Sciences USA, vol. 93, no. 14, pp. 7091-7096.

Love, A., 2007, "Functional Homology and Homology of Function: Biological Concepts and Philosophical Consequences", Biology and Philosophy, vol. 22, no. 5, pp. 691-708. 
Mayr, E., 1969, Principles of Systematic Zoology, McGraw-Hill, Nueva York.

Millikan, R.G., 1984, Language, Thought, and Other Biological Categories, The MIT Press, Cambridge, Mass.

Minelli, A., 1998, "Molecules, Developmental Modules, and Phenotypes: A Combinatorial Approach to Homology", Molecular Phylogenetics and Evolution, vol. 9, no. 3, pp. 340-347.

Mooi, R.D. y A.C. Gill, 2010, "Phylogenies without Synapomorphies-A Crisis in Fish Systematics: Time to Show Some Character", Zootaxa, vol. 2450, pp. 26-40.

Müller, G.B., 2003, "Homology: The Evolution of Morphological Organization", en G.B. Müller y S.A. Newman (comps.), Origination of Organismal Form: Beyond the Gene in Developmental and Evolutionary Biology, The MIT Press, Cambridge, Mass., pp. 51-70.

Neander, K., 1995, "Misrepresenting and Malfunctioning", Philosophical Studies, vol. 79, pp. 109-141.

— , 1991, "The Teleological Notion of "Function", The Australasian Journal of Philosophy, vol. 69, no. 4, pp. 454-468.

Nelson, G., 2011, "Resemblance as Evidence of Ancestry", Zootaxa, vol. 2946, pp. 137-141.

Nixon, K.C. y J.M. Carpenter, 2012, "More on Homology", Cladistics, vol. 28, no. 3, pp. 225-226.

Owen, R., 1843, Lectures on the Comparative Anatomy and Physiology of the Invertebrate Animals, Longman, Brown, Green and Longmans, Londres.

Patterson, C., 1988, "Homology in Classical and Molecular Biology", Molecular Biology and Evolution, vol. 5, no. 6, pp. 603-625.

—_, 1982, "Classes and Cladists or Individuals and Evolution", Systematic Zoology, vol. 31, no. 3, pp. 284-286.

Platnick, N.I., 2013, "Less on Homology", Cladistics, vol. 29, no. 1, pp. 10 12.

Remane, A., 1952, Die Grundlagen des natürlichen Systems, der vergleichenden Anatomie und der Phylogenetik, Akademische Verlags gesellschaft, Leipzig.

Richards, R., 2003, "Character Individuation in Phylogenetic Inference", Philosophy of Science, vol. 70, no. 2, pp. 264-279.

Rieppel, O., 2007, "The Nature of Parsimony and Instrumentalism in Systematics", Journal of Zoological, Systematics and Evolutionary Research, vol. 45, no. 3, pp. 177-183.

Rieppel, O. y M. Kearney, 2007, "The Poverty of Taxonomic Characters", Biology and Philosophy, vol. 22, pp. 95-113.

Scotland, R., 2011, "What is Parallelism?", Evolution \& Development, vol. 13, no. 2, pp. 214-227.

Sober, E., 2008, Evidence and Evolution: The Logic Behind the Science, Cambridge University Press, Cambridge, UK. 
Striedter, G.F. y G.R. Northcutt, 1991, "Biological Hierarchies and the Concept of Homology", Brain, Behavior and Evolution, vol. 38, no. 45, pp. 177-189.

Wagner, G.P., 2007, "The Developmental Genetics of Homology", Nature Reviews: Genetics, vol. 8, pp. 473-479.

Williams, D.M., M.C. Ebach y M.R. de Carvalho, 2011, “Opening Pandora's Molecular Box", Zootaxa, vol. 2946, pp. 60-64.

Recibido el 13 de agosto de 2012; revisado el 7 de octubre de 2013; aceptado el 19 de febrero de 2014. 